\title{
Indigenous Nature Connection: A 3-Week Intervention Increased Ecological Attachment
}

\author{
Angela M. Kurth, Darcia Narvaez, Reilly Kohn, and Andrea Bae ${ }^{2}$ \\ ${ }^{1}$ Department of Psychology, University of Saint Thomas, Saint \\ Paul, Minnesota, USA. \\ ${ }^{2}$ Department of Psychology, University of Notre Dame, Notre \\ Dame, Indiana, USA.
}

\section{Abstract}

Humanity as a species has spent most of its existence moving with instead of against nature as found among Indigenous or First Nation communities traditionally. Yet most members of modern societies feel disconnected from nature, which is attributed to a lack of connection and respect toward the more than human. We developed assessment tools for ecological attachment from an Indigenous perspective, validating measures $(\mathrm{n}=695)$ of ecological empathy (feeling concern for more-than-human entities), ecological mindfulness (mindful attitudes and behaviors toward living things), and green action (conservation behaviors). Then we conducted a 3-week behavioral intervention with university students $(\mathrm{n}=47)$ with two conditions expected to increase ecological mindfulness: (1) Indigenous ecological attachment (e.g., acknowledge the trees you pass today) by which ecological empathy was expected to increase; (2) conservation behaviors (e.g., turning off lights) by which green action was expected to increase. In session one, participants completed key measures, read texts related to their condition (facts, a poem, and an essay), and selected condition-relevant actions to draw from and perform in the following 3 weeks (one selected per day). In session two, measures were retaken. In comparison with a control group, MANOVA revealed that hypotheses were supported: Only the ecological attachment group increased on ecological empathy, only the conservation group significantly increased on green actions, and both intervention groups increased on ecological mindfulness. Key Words: Indigenous worldview-Behavior change-Ecopsychology-BiophiliaConnection to nature.

\section{Introduction}

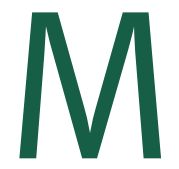

any studies in environmental psychology have emphasized a longstanding worldview of the last centuries, that humans are actors and that nature is largely inert (Merchant, 1983). Such studies aim to increase conservation behaviors such as recycling or water conservation by increasing knowledge about effects and thereby hoping to change attitudes and behavior. But merely learning how to reduce consumption does not necessarily lead to increases in corresponding behavior (Kollmuss \&t Agyeman, 2002; see Abrahamse, Steg, Vlek, \&t Rothengatter, 2005, for a review). Nor does a positive attitude toward energy conservation consistently lead to behavior change (Costanzo, Archer, Aronson, \& Pettigrew, 1986; Kollmuss \& Agyeman, 2002). In effect, many attempts at inciting behavior change have not been successful (Ro, Brauer, Kuntz, Shukla, \&t Bensch, 2017).

Amel, Manning, Scott, and Koger (2017) note that at the root of the current ecological crisis is the fact that individuals view themselves as separate from the natural world, a view initiated by the Cartesian revolution (Moore, 2015; Worster, 1994). The human relationship with the environment evolved over the last centuries to become increasingly one sided. The one-sided relationship grew to be devoid of much emotion, as plants and animals were seen as mere objects in nature ("resources") without purposes of their own. Industrialized societies developed a practical reliance on the environment, taking and using resources, typically without much regard for nature's wellbeing, despite warnings by observers for the past couple of centuries (e.g., Wulf, 2015). More recently, the lines between humans and nature may have become less stark as interest in a green economy-an 


\section{KURTH ET AL.}

economy that is sustainable and reduces environmental risks and degradation-has increased (Bernstein, Szuster, \& Phillips, 2017).

Despite these moves, attitudes and behavior have not shifted enough or perhaps in the way needed. Berry (2013) noted that while an intellectual approach to the environmental crisis can be helpful, over decades it has not changed fundamental practices. What is needed instead is "informed, practical, and practiced affection" for humanity to be able to break out of its current state of ecological crisis, revitalize, and maintain a sustainable lifestyle (Berry, 2013, p. 14, italics added). It is essential, he argues, that people sense their well-being is intertwined with the well-being of the planet as a whole. Simply raising awareness of the crisis at hand, or even understanding it, does not address the rupture in the relationship between humans and the more than human. Indeed, some researchers propose that an "ecological self"-a self-identity that feels "continuous" with nature, holding a sense of connectedness and oneness between the self and the larger natural world-is key to environmental action because it shapes both values and action (Naess, 1985; see also Bragg, 1996; Kidner, 2001). With this in mind, the Connectedness to Nature Scale (CNS; Mayer \& Frantz, 2004) was developed to measure an individual's emotional and affective relationship with the natural world and to lifestyle patterns and ecological behavior. Testing the CNS, Mayer and colleagues (Mayer, Frantz, Bruehlman-Senecal, \& Dolliver, 2009) compared three conditions: watching videos of natural and urban settings, walking through urban settings, or walking through natural settings. The immersion studies demonstrated that experience with and engagement in the natural world were associated with an increase in attentiveness, positivity, and CNS scores. Direct contact, moreover, was more impactful than indirect, virtual experience.

What mechanism lies behind the increase in connectedness to nature? Some posit that empathy for the natural world is an important mechanism that can help strengthen a positive relationship between the self and nature. For example, when participants were shown photographs and asked to take the perspective of animals shown being harmed by environmental conditions, the participants experienced an increase in biospheric concern, or concern for all living things (Schultz, 2000), an effect assumed to be due to an increase in empathy (Sevillano, Aragones, \& Schultz, 2006). Adopting an ecological-self perspective, meaning that the view of the self is integrated with the natural world, is associated with increases in ecological behavior in that participants who increased in empathy for the biosphere tended to increase in willingness to allocate money to wild species conservation and environmental education (Berenguer, 2007). Such studies suggest that an ecological-self perspective requires adjustments in cognition, emotion, and motivation that result in increased empathy and connection to nature, thereby shifting values toward environmental concern (Bragg, 1996).

Humanity as a species has spent most of its existence moving with instead of against nature, feeling integrated with the local landscape and responding cooperatively to its rhythms (Descola, 2013), corresponding with an Indigenous worldview (Four Arrows \& Narvaez, 2016; Redfield, 1953). Daily practices of attending to the well-being of the more than human characterize First Nation communities. The individual understands himself or herself as integrated into, instead of feeling apart from, the natural world (Narvaez, Four Arrows, Halton, Collier, \& Enderle, 2019). Traditional ecological knowledge (TEK) represents wisdom gained from thousands of years of observational and immersed human experience, which some have suggested is a perspective required for sustainable development (Berkes, Folke, \& Gadgil, 1995). Similarly, scholars have pointed out the parallels between the Indigenous worldview and the "deep ecology" movement, which reaches beyond the surface level "symptoms" of the ecological crises, to focus on underlying value systems and worldviews which can be engaged via social change in political, educational, spiritual practices (Booth, 2000; Bragg, 1996; Naess, 1973). As noted by Nadasdy (2005), First Nation communities commonly display a deep reverence for nature and a belief in the oneness of humans and nature, though not the ecocentrism of deep ecology. Amel and colleagues (2017) suggested that a return to Indigenous perspectives is critical to revitalize the relationship between humanity and the rest of the biosphere. Some have already begun this work by embedding Indigenous teachings in sustainability pedagogy (Burns, 2015) and examining the role of TEK in adapting to climate change in the Canadian Arctic, because of Indigenous knowledge of coping with environmental change (Pearce, Ford, Willox, \& Smit, 2015). The current studies attempted to examine and promote this kind of Indigenous perspective toward the natural world-a perspective that is both mindful of and empathic with more-than-human entities as part of one's relational community.

\section{Current Studies}

Existing measures of environmental attitudes tend to emphasize connection with nature generally and awareness of ecological problems (e.g., CNS, New Ecological Paradigm [NEP]). However, NEP, a measure of proecological worldview, may be outdated because environmental problems and our understanding of them have shifted (LaLonde \& Jackson, 2002). In some ways, public perception regarding the opposition between humans and nature has shifted with an incorporation of proenvironmental values with economic and 


\section{NATURE CONNECTION}

technological advancements (Bernstein et al., 2017). Even so, not all viewpoints have been captured in existing measures.

One area that is not addressed in current measures, specifically NEP and CNS, is an Indigenous orientation to the natural world-treating entities in nature as sentient and members of one's community. In response to this gap, we created and tested items based on the reading of multiple Indigenous sources (e.g., Cajete, 2000; Cooper, 1998; Deloria, 2006; Four Arrows, 2016; WindEagle \& RainbowHawk, 2003). Although the CNS measures feelings of connection toward the natural world, we wanted to test items reflecting relational concern (ecological empathy). Rather than focusing on awareness of the state of ecology as NEP tests, a new set of items (ecological mindfulness) focused on intentional awareness and action toward natural entities.

After several pilots, we selected two sets of items to further analyze. One set reflected feelings of empathy and concern for the more than human (e.g., an animal, a tree), which was mixed with items about other concerns a person might have. The second set included intentional behavior toward entities in the natural world (e.g., making decisions with humility as one of many earth creatures) along with other influences on one's decisions. The aim of the pilot study was to employ exploratory factor analysis (EFA) to establish coherent sets of items. Methodology for all following studies was approved by the institutional review board.

\section{Pilot Study}

\section{Method}

Participants and procedure. Using Amazon Mechanical Turk (MTurk), 450 US adults (48\% male, $M_{\text {age }}=37.48, S D=12.8 ; 77.8 \%$ Euro-American; $12 \%$ with high school diploma or less; $37 \%$ with some college; 36\% with bachelors, 14\% with higher degree) responded to online surveys. Socioeconomic status was assessed in terms of basic needs with 18.2\% lacking or sometimes lacking funds for basic needs, $43.8 \%$ saying they had enough money for basic needs but not extras, and $38.1 \%$ saying they had enough for basic needs and extras.

Measures. Several sets of items were compiled. Participants responded to the first set of items $(n=47)$ regarding the frequency of feelings and concern in the past week, and the second set $(n=39)$ regarding the frequency in the past week of mindful actions and thoughts one might have $(1=$ never, $5=$ multiple times a day).

Another set of items was compiled to assess "green action," based on several existing lists, to form a comprehensive checklist of "green" behaviors but split into two lists: actions completed on a frequent basis and actions that occur infrequently or seasonally (see Appendix A).
The frequent list, called Daily Green Action (36 items, e.g., "Reduced use of disposable products by using reusable containers"), assessed frequency in the past week $(1=$ never, $5=$ multiple times $a$ day $)$. The less frequent list, called Six-Month Green Action (15 items, e.g., "Grew my own vegetables"), assessed frequency in the past six months ( $1=$ never, $7=$ more than 12 times). Because we believed that people would likely perform an array of actions, not specific groupings, we did not expect the green action measures to cohere to specific factors. Therefore, factor analysis was not performed on these indices.

\section{Results and discussion}

We performed EFA on the environmental empathy and mindfulness items, separately, using varimax rotation. Four factors were extracted from the empathy items, with the first factor capturing the target construct most closely, so it was kept for a measure called "ecological empathy." See Table 1 for factor loadings. Four factors also emerged from the second set of 39 items regarding thoughtful action. The first factor again best reflected the target construct and was kept as a measure called "ecological mindfulness." See Table 2. Ecological empathy includes items that assess empathy expressed for both humans and the more than human, while ecological mindfulness is a collection of attitudes and behaviors that reflect cooperation and intentional awareness of natural entities. Following the pilot study, we collected additional data to assess validity.

\section{Study 1}

The goal of Study 1 was to finalize the two new scales, ecological empathy and ecological mindfulness, with confirmatory factor analysis (CFA). Then, using correlation, we assessed convergent validity with existing measures of nature connectedness, divergent validity with existing measures of empathy and perspective taking, and concurrent validity with the green action index. We wanted to assess how ecological empathy and ecological mindfulness would relate to green behavior, and whether existing measures of ecological connectedness would relate to our green behavior indices. We also predicted that ecological empathy and ecological mindfulness would be modestly related to but also distinctive from sociomoral variables, specifically empathy and perspective taking, based on previous research (Schultz, 2000; Sevillano et al., 2006). We expected personal distress to be negatively correlated with measures of nature connection and ecological attachment.

\section{Method}

Participants. Adults were recruited from MTurk. Of the 695 US adults, $45.9 \%$ were male, ages $18-75\left(M_{\text {age }}=35.70, S D=11.90\right.$; 


\section{Table 1. Factor Loadings for Ecological Empathy}

\section{ITEM STEM: "IN THE PAST WEEK,}

\section{FELT CONCERN FOR}

... the natural world

... a particular species

... an animal going extinct

... an animal I don't know

... an insect

... a tree

... a forest

... a plant

... a mountain

... a river

... a lake or pond

... the ocean $(\mathrm{s})$

... biodiversity

... groups of animals

... the wellbeing of the earth

... bringing about world peace

... walking softly on the earth

... being humble before Nature

... an animal I know

... people in my family

... creating something beautiful

... being respectful

... being kind

... being patient

... being tolerant

... being loving

... being compassionate

... creating something useful

\section{FACTOR LOADINGS}

ECOLOGICAL EMPATHY

FACTOR 2

FACTOR 3

FACTOR 4
.68

.76

.69

.71

85

.85

.73

.72

.78

.79

.79

.76

.72

79

.66

.50

.65

.63

.41 
NATURE CONNECTION

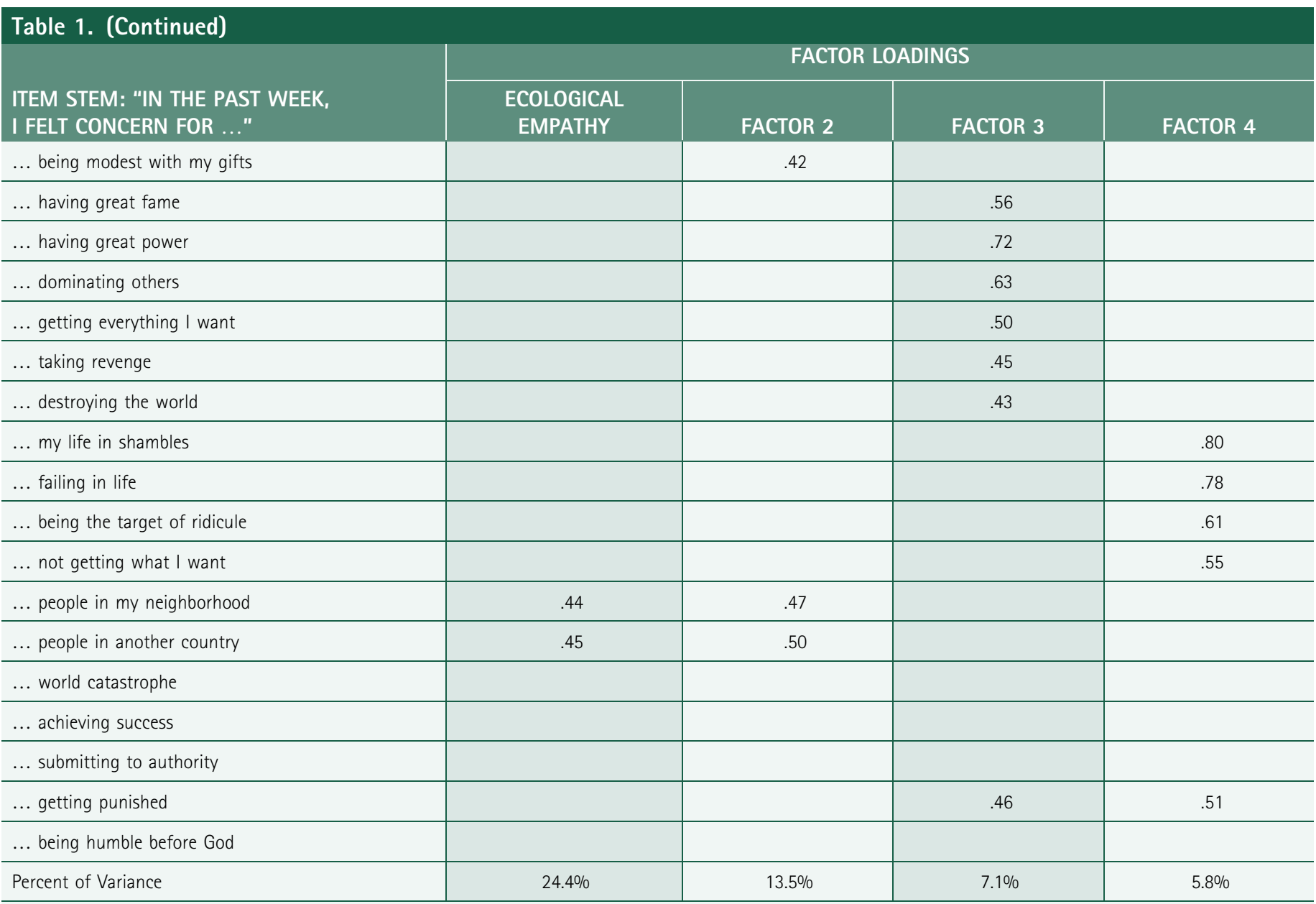

Factor loadings below 4 are excluded from the table. $(n=47)$

81.7\% Euro-American; $14.1 \%$ with a high school diploma or less, $37.9 \%$ with some college, $34.0 \%$ with a bachelor's degree, $13.6 \%$ with a higher degree). Regarding finances, 21.2\% reported lacking or sometimes lacking enough money for basic needs, 39.4\% reported having enough money for basic needs but not extras, and 39.2\% said they had enough for basic needs and extras.

\section{Confirmatory factor analysis and final scales}

The model fit of the two measures as a set was tested using CFA with Yuan-Bentler correction (Yuan \& Bentler, 2000), performed in R (R Core Team, 2016) using the lavaan package (Rosseel, 2012). Best fit was obtained with the two-factor model when five items were eliminated based on low factor loadings and alphas (CFI $=.92$, RMSEA $=.07$ ). Internal reliability of the final measures was excellent (ecological empathy $\alpha=.96$; ecological mindfulness $\alpha=.95$ ). See Appendix A for final measures.

Measures. Mean scores were used, and higher scores indicate endorsement of the variable's construct unless otherwise noted. There were six environmental measures, including two assessing behavior. There were three measures of sociomoral capacities.

Ecological empathy. Empathy for humans and the more than human (e.g., "In the past week, I remember feeling sympathy/concern for the wellbeing of the earth") was measured using a 5-point Likerttype scale $(n=16 ; \alpha=.96 ; 1=$ never, $5=$ multiple times $a$ day). 


\section{Table 2. Factor Loadings for Ecological Mindfulness}

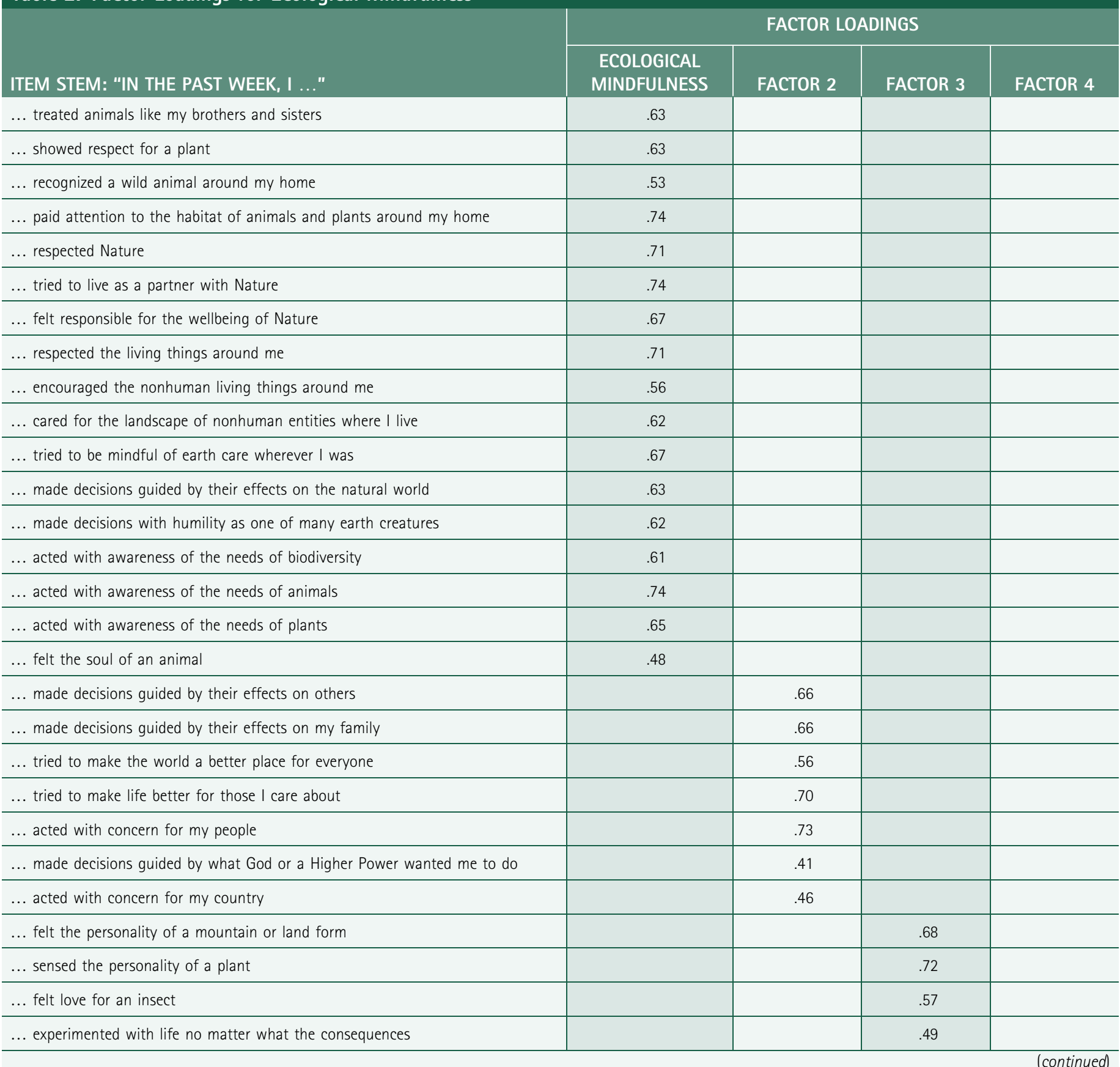


NATURE CONNECTION

\begin{tabular}{|c|c|c|c|c|}
\hline \multirow[b]{2}{*}{ ITEM STEM: "IN THE PAST WEEK, I ..." } & \multicolumn{4}{|c|}{ FACTOR LOADINGS } \\
\hline & $\begin{array}{l}\text { ECOLOGICAL } \\
\text { MINDFULNESS }\end{array}$ & FACTOR 2 & FACTOR 3 & FACTOR 4 \\
\hline ... made decisions guided by their effects on my religious community & & & .48 & \\
\hline ... did anything I felt like doing & & & & .78 \\
\hline ... did whatever felt good & & & & .79 \\
\hline ... had a sense of freedom to do whatever I wanted & & & & .53 \\
\hline ... tried to make life better just for myself & & & & .44 \\
\hline ... paid attention to the welfare of living things around me (13) & .66 & .46 & & \\
\hline ... acted with awareness of the needs of humanity (35) & .51 & .52 & & \\
\hline$\ldots$ felt disgusted by an insect (9) & .42 & .47 & & \\
\hline$\ldots$ felt at home on the land where I live (17) & & .45 & .41 & \\
\hline \multicolumn{5}{|l|}{... made decisions guided by their effects on people I don't know (26) } \\
\hline \multicolumn{5}{|l|}{... made decisions guided by what other people wanted me to do (28) } \\
\hline Percent of Variance & $23.2 \%$ & $11.8 \%$ & $9.1 \%$ & $5.3 \%$ \\
\hline
\end{tabular}

Factor loadings below .4 are excluded from the table. $(n=39)$.

Ecological mindfulness. Cooperative attitudes and behaviors and intentional awareness of living things (e.g., "In the past week, I treated a plant with respect") were measured using a 5-point Likerttype scale $(n=15 ; \alpha=.95 ; 1=$ never, $5=$ multiple times $a$ day).

Connectedness to Nature Scale (CNS). Emotional connection to the natural world (Mayer \& Frantz, 2004; $n=14 ; \alpha=.81$ ) was measured with a 5-point Likert-type scale ( $1=$ strongly disagree, $5=$ strongly agree; e.g., "I often feel part of the web of life").

New Ecological Paradigm (NEP). Cognitive understanding of environmental issues (Dunlap, Van Liere, Mertig, \& Jones, 2000; $n=15$; $\alpha=.91)$ was measured using a 5-point Likert-Type scale ( $1=$ strongly disagree, $5=$ strongly agree; e.g., "The balance of nature is very delicate and easily upset”).

Daily Green Action Index. The frequency in which the participant engaged in environmentally conscious activities in the past week using a 5-point Likert-type scale $(1=n e v e r, 5=$ multiple times a day; $n=36$; e.g., "Used cloth instead of paper napkins").

Six-Month Green Action Index. The frequency in which participants engaged in nondaily green actions using a 7-point Likert-type scale $(1=$ never, $7=$ more than 12 times; $n=15$; e.g., "Grew my own vegetables").

Sociomoral capacities. The Interpersonal Reactivity Index (IRI; Davis, 1983) was used to capture three sociomoral orientations, empathy ( $n=7 ; \alpha=.64$; e.g., "I often have tender, concerned feelings for people less fortunate than me"), perspective taking $(n=7 ; \alpha=.86$; e.g., "I try to look at everybody's side of a disagreement before I make a decision"), and personal distress ( $n=7 ; \alpha=.84$; "I tend to lose control during emergencies"), each rated on a 5-point Likert-type scale $(1=$ does not describe me well, $5=$ describes very well).

\section{Results and discussion}

See Table 3 for means and standard deviations. See Table 4 for correlations assessing relationships among variables.

Convergent validity. Ecological empathy and ecological mindfulness moderately correlated with existing measures of CNS and NEP, suggesting that they are tapping into distinctive aspects of nature connection. The largest correlation was between ecological 


\section{KURTH ET AL.}

\begin{tabular}{|c|c|c|c|}
\hline VARIABLE & $M(S D)$ & RANGE & $\alpha$ \\
\hline Ecological Empathy & $2.64(0.99)$ & $1-5$ & .959 \\
\hline \multicolumn{4}{|l|}{ Convergent Validity } \\
\hline Connectedness to Nature & $3.43(0.59)$ & $1-5$ & .809 \\
\hline \multicolumn{4}{|l|}{ Divergent Validity } \\
\hline Empathy & $3.72(0.58)$ & & .708 \\
\hline Perspective Taking & $3.80(0.70)$ & & .557 \\
\hline Personal Distress & $2.49(0.83)$ & & .593 \\
\hline Six-Month Green Action Index & $36.98(16.27)$ & $15-105$ & .893 \\
\hline
\end{tabular}

mindfulness and CNS, suggesting that the CNS measure may be assessing more cognitive than emotional aspects.

Divergent validity. Ecological empathy was weakly correlated with empathy and perspective taking, and ecological mindfulness was moderately correlated with empathy and perspective taking but negatively related to personal distress. While the relations among ecological mindfulness and empathy and perspective taking were quite similar in strength and direction as the CNS, the negative relation between ecological mindfulness and personal distress suggests that being self-preoccupied dampens mindfulness toward the natural world. Further, CNS and ecological mindfulness were only moderately correlated with one another, suggesting that ecological mindfulness is tapping into something slightly different.

Concurrent validity. The two behavior indices, daily green action index and six-month green action index, were strongly correlated with each other. They were both moderately correlated with existing measures of ecological concern (CNS and NEP). Both behavior measures were strongly related to ecological empathy and moderately correlated with ecological mindfulness, suggesting that ecological empathy or feelings of sympathy toward nature may drive green action more than mindfulness or intentional awareness toward nature.
Given the suggestions that empathy for and a sense of connection to nature may be important mechanisms for repairing the relationship between the self and nature (Naess, 1985; Schultz, 2000; Sevillano et al., 2006) and improving environmental behavior (Berenguer, 2007), the relationships among variables here showed promise.

In a second study, we used the new assessment tools to measure change from behavior intervention. By altering participants' behavior with an intervention, we expected to inspire improvements in attitudes and behavior toward the natural world. Our approach mimics the "ecological self" approach to behavior change, which in the past has been successful at developing the self through intensive workshops (Macy \& Brown, 1998; Seed, Macy, Fleming, \&t Naess, 1988) and in wilderness settings (Coburn, 2006; Williams \& Harvey, 2001). The ecological self may be developed through sensitive reading of poems or through gardening, meditating, and hiking (Koger \& Winter, 2010). We took advantage of campus sources with a steady population to test self-directed daily action.

\section{Study 2}

Amel and colleagues (2017) suggested the goal of behavior studies should be to methodically empower individuals to change their behavior, which requires not only education but also effective tools and 
NATURE CONNECTION

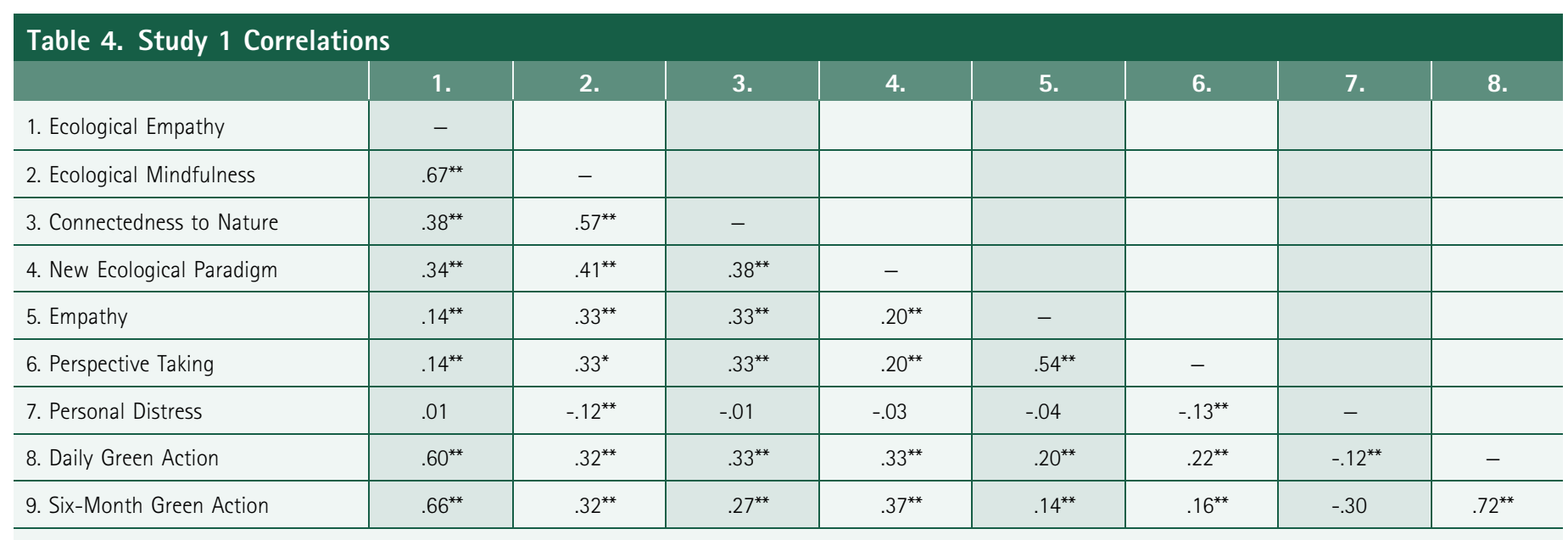

${ }^{*} p<0.05 ;{ }^{* *} p<0.01$.

courage for behavior change. The aim of Study 2 was to test whether we could alter Indigenous ecological attachment (ecological mindfulness and ecological empathy) with a behavioral intervention to help participants reconnect to the natural world. As Amel et al. (2017) pointed out, there are initial difficulties in adopting sustainable behavior, so we followed the behavior change model suggested by Heath and Heath (2010), where one must take a three-pronged approach: First, "direct the rider"-alert the intellect or explicit mind that the behavior change is needed. Second, "motivate the elephant"-move the implicit mind through habits, emotions, and intuitions. Third, "shape the path" with specific steps to be taken. Unlike the design implemented by Mayer and colleagues (2009), whose conditions involved one-time immersion experiences, our study used daily exposure over 3 weeks. We aimed to facilitate a mindset shift with the daily practices adopted by participants. Specific interventions (sustainable groceries) have been effective at changing very specific behaviors (Hanss \& Bohm, 2013). We thought that specific actions selected by participants might influence not only their daily behavior but their attitudes. We assigned two conditions and measured effects on ecological empathy and mindfulness. We hypothesized that the Indigenous ecological attachment condition would increase ecological empathy scores, that the conservation condition would increase green action scores, and that both groups would increase ecological mindfulness scores. Because others have found that immersion in nature has restorative effects (Cooper Marcus \& Barnes, 1999), we hypothesized that stress would decrease only for those in the ecological attachment condition.
Method

Participants. Study participants were 93 undergraduate volunteers (69 female; age 18-30; $M_{\text {age }}=19.13, S D=1.64 ; 79.6 \%$ White/EuroAmerican; 55.9\% freshmen) who received course credit for participating. Since the participants were students and perhaps not aware of their parents' household income, we did not collect socioeconomic information. In both conditions, all participants reported completing at least $60 \%$ of the daily tasks (completion rate ranged from 60$100 \%)$, so none were removed from the analysis.

Measures. Each measure was administered before and after the intervention. There were three target variables: ecological empathy, ecological mindfulness, and daily green action. We also examined reported stress.

Ecological measures. The same measures of ecological empathy, ecological mindfulness, and daily green action index as described in Study 1 were used.

Stress. Participants reported on stress by responding to a single item: "On average in the last week, how stressed did you feel?" using a 5-point Likert-type scale ( $1=$ not at all stressed, $5=$ very stressed $)$.

Procedure. Participants who came to the lab were assigned to a condition in groups of three. There were two conditions: Indigenous Ecological Attachment and Conservation. A control group was collected separately, taking online pre-post measures 3 weeks apart. The experimental groups visited the laboratory to complete a pretest survey and a set of readings corresponding to the condition to which 


\section{KURTH ET AL.}

\begin{tabular}{|c|c|c|c|c|c|c|c|c|c|c|c|c|}
\hline & \multicolumn{3}{|c|}{ FULL SAMPLE } & \multicolumn{3}{|c|}{ CONSERVATION CONDITION } & \multicolumn{3}{|c|}{ ECOLOGICAL ATTACHMENT CONDITION } & \multirow{2}{*}{$\begin{array}{l}\text { CONTROL GROUP } \\
M(S D)\end{array}$} & \multirow[b]{2}{*}{ MIN } & \multirow[b]{2}{*}{ MAX } \\
\hline & $M(S D)$ & MIN & MAX & $M(S D)$ & MIN & MAX & $M(S D)$ & MIN & MAX & & & \\
\hline Ecological Empathy Pretest & $1.62(0.48)$ & 1.00 & 3.38 & $1.56(0.31)$ & 1.00 & 2.06 & $1.59(.49)$ & 1.00 & 2.75 & $1.73(0.54)$ & 1.00 & 3.38 \\
\hline Ecological Empathy Posttest & $1.98(0.64)$ & 1.00 & 3.69 & $1.81(0.49)$ & 1.00 & 2.81 & $2.37(0.62)$ & 1.44 & 3.63 & $1.89(0.65)$ & 1.00 & 3.69 \\
\hline Ecological Mindfulness Pretest & $2.39(0.75)$ & 1.20 & 4.53 & $2.15(0.67)$ & 1.33 & 3.87 & $2.42(0.76)$ & 1.27 & 3.80 & $2.50(0.78)$ & 1.20 & 4.53 \\
\hline Ecological Mindfulness Posttest & $2.47(0.80)$ & 1.00 & 4.47 & $2.41(0.68)$ & 1.27 & 3.87 & $2.88(0.75)$ & 1.60 & 4.47 & $2.31(0.84)$ & 1.00 & 4.27 \\
\hline Green Action Index Pretest & $2.88(0.65)$ & 1.58 & 4.39 & $2.61(0.57)$ & 1.83 & 4.11 & $2.99(0.56)$ & 2.00 & 4.39 & $2.98(0.70)$ & 1.58 & 4.08 \\
\hline Green Action Index Posttest & $2.96(0.67)$ & 1.08 & 4.78 & $2.96(0.51)$ & 2.00 & 3.97 & $3.10(0.63)$ & 2.14 & 4.78 & $2.89(0.76)$ & 1.08 & 4.44 \\
\hline
\end{tabular}

Full sample $n=47$, Conservation Condition $n=25$, Ecological Attachment Condition $n=22$, Control group $n=46$.

they were assigned. The readings included facts, a poem, and an essay, followed by a reading comprehension test. Then they were told to select 21 items from up to 41 actions that would form a group from which they would daily, for each day of 3 weeks, select one to perform throughout that day. See Appendix B for the item lists. Actions were not to be repeated. Sample actions included Indigenous ecological attachment condition: "Establish a relationship with a tree near your dorm"; conservation condition: "Turn the water tap off when brushing teeth."

The actions that participants chose were put in an envelope that they took with them. They were instructed to draw randomly from the envelope each morning for the following 3 weeks and place the action in a separate envelope after it was performed. Over the course of the three weeks, participants were e-mailed daily to remind them to select and perform a new action and report on which action they performed. After 3 weeks, participants returned to the lab to take posttest surveys.

\section{Results and discussion}

Means and standard deviations for target variables are displayed in Table 5. To test each hypothesis, a $3 \times 3$ MANOVA was used. MANOVA revealed significant effects of condition on all three ecological variables: ecological empathy $(F(2,90)=9.10 ; p<.001)$, ecological mindfulness $(F(2,90)=7.55 ; p<.001)$, and green action $(F(2,90)=1.66 ; p<.01)$. Using Bonferroni correction, these tests all remain significant. Results of Tukey's post-hoc tests are described below, by hypothesis.

Ecological empathy. For the first hypothesis, that ecological empathy scores would increase only for the Indigenous ecological attachment group, Tukey's post-hoc tests revealed significant differences on ecological empathy for the ecological attachment condition compared to the control group $(p<.001)$ and between the ecological attachment condition and the conservation condition $(p<.05)$ but no significant difference between the conservation condition and the control group ( $p=.38)$. The first hypothesis was supported.

Green action. For the second hypothesis, Tukey's post-hoc tests revealed significant differences on green action for only the conservation condition compared to the control group $(p<.01)$ but not the Indigenous ecological attachment condition compared to the control group ( $p=.33$ ) or the Indigenous ecological attachment compared to the conservation condition $(p=.27)$. The second hypothesis was supported.

Ecological mindfulness. To test the third hypothesis, the increase in ecological mindfulness for experimental conditions, Tukey's posthoc tests revealed significant differences from the control group on ecological mindfulness for both Indigenous ecological attachment $(p<.01)$ and conservation conditions $(p<.05)$ and not from one another $(p=.60)$. The third hypothesis was supported.

Stress. To test the fourth hypothesis, that the Indigenous ecological attachment group would exhibit decreased scores on stress, we used ANOVA, which indicated that there were no significant in-group change scores on stress $F(2)=0.10, p>.05$. We speculate that performing unfamiliar tasks and responding to a daily survey increases stress for busy students, which minimized the stress-relieving effects of the actions. We did, however, attempt to mitigate the stress of the intervention by allowing students to choose their daily actions from a 


\section{NATURE CONNECTION}

larger pool of possible behaviors. But perhaps that was insufficient. We also did not control for time in the semester, and exams and coursework due dates may have been factors as well.

Taken together, the results of the intervention suggest that performing ecological attachment actions improves ecological empathy and that both types of interventions can improve scores on ecological mindfulness.

\section{General Discussion}

We created several measures to investigate ecological orientations. After testing and validating ecological empathy and ecological mindfulness measures, representative of an Indigenous ecological orientation, we conducted an intervention study to examine the effects of daily behavior practice on attitudes and behaviors. We attempted to increase orientations to ecological issues by having participants practice actions on a daily basis. In the intervention study, we followed Heath and Heath's (2010) program for behavior change. (a) Direct the rider: We did this with the readings at the first session. (b) Motivate the elephant: We did this with extra-credit incentives. (c) Third, we "shaped the path" by providing a specific daily task over 3 weeks. One thing we did not provide was an explicit goal to be aimed for, which is the typical approach in intervention research. Instead, we were more focused on shifting implicit systems of habits and preferences (the "elephant"). We review the findings.

\section{Ecological attachment}

The target condition focused on increasing Indigenous ecological attachment through daily attention to entities in the natural environment. Scores increased on ecological empathy and ecological mindfulness, which conforms with work showing that an increase in empathy fosters an increase in ecological self-concept or connection to nature, which in turn increases biospheric values (Schultz, 2000; Sevillano et al., 2006). Other studies have found that mindful practices in nature, similar to actions assigned to the Indigenous ecological attachment group, have been found not only to increase connection to the ecosystem (Cahalan, 1995; Macy \& Brown, 1998; Swanson, 2001) but to decrease consumption (De Wet, 2008; Goleman, 2009), ecological footprint (Brown \& Kasser, 2005), materialistic values, or increase environmentally friendly behavior (Amel, Manning, \&t Scott, 2009). We did not expect ecological empathy to increase for the conservation group because no behaviors were focused on building empathy; nevertheless, the group did show an increase in scores on ecological empathy.

Both groups increased in ecological mindfulness, not a surprise for the Indigenous ecological attachment group. In the conservation condition, we did not intentionally target value change, apart from the information presented in session one, but participants had control over carrying out a particular behavior all day long, which we expected to increase awareness of conservation behaviors.

\section{Conservation behavior}

We were neutral on whether the Indigenous ecological attachment group would improve on green behavior, and they did not. This is not a surprise because, for example, there are cognitive steps between turning off lights and connecting to a tree. Conservation behaviors are rooted in executive functions of inhibitory control (e.g., shorten a shower) and prospective memory (e.g., avoid turning on a light), whereas the ecological attachment tasks were about enhancing emotional-relational presence. For the conservation group, the intervention increased scores on reported green action as expected. Perhaps in a future study, these conditions could be combined; adding additional phases of the intervention focused on green behavior could promote a connection between ecological attachment and green behavior.

\section{Future directions}

Often, people do not engage in sustainable behaviors, because they believe their individual actions are insignificant in the face of the overwhelming size of the problem (Gifford, 2011; Tabanero \& Hernandez, 2011). A lack of self-efficacy contributes to lack of action (Lauren, Fielding, Smith, \& Louis, 2016). Future research could examine whether our ecological attachment intervention enhances nature connection self-efficacy, a sense of oneness that typically includes a sense of reverence. Value change over time should also be explored. Do biospheric values increase? Values Beliefs Norms theory (VBN; Dietz, Fitzgerald, \& Shwom, 2005) suggests that values, though stable and difficult to change, influence beliefs and predict behaviors. But VBN notes that people will engage in environmentally friendly behavior in situations that activate personal norms only if one's values are tied to the environment (Stern, 2000; Stern, Dietz, \& Kalof, 1993). Supporting the theory, feelings of personal obligation, especially moral responsibility, have been predictive of proenvironmental behaviors (Bratt, 1999; Kaiser, Ranney, Hartig, \& Bowler, 1999; Widegren, 1998). Do interventions like this one actually change personal values, and thereby long-term behavior, toward the environment?

Our interventions gave some but little control to the participants. Studies have found that values have a greater influence on behavior when there is more personal control over behavior, whereas more constrained behaviors are less influenced by personal values (Black, 


\section{KURTH ET AL.}

Stern, \&t Elworth, 1985). In addition, planning ahead of time can be more predictive of behavior than proenvironmental values per se (Goh, Ritchie, \& Wang, 2017), which suggests that incorporating a planning component could be even more effective than randomly selecting actions to perform each day. Others found that people engage with environmental issues for differing reasons, including concern for themselves, others, or the biosphere (Hansla, Gamble, Juliusson, \& Garling, 2008), corresponding with the individual's awareness-ofconsequences for each entity (self, other, biosphere; Hansla et al., 2008). Thus, emphasizing impacts on natural entities in combination with immersive practices, as in our experimental conditions, may further increase the ecological engagement and ecological mindfulness.

Further studies could examine the consequences of emphasizing the emotive ecological empathy or the more cognitive ecological mindfulness and how they interact. The ecological attachment intervention could be further enhanced by using other methods to direct the rider, such as framing information in order to emphasize current and local impacts, motivating the elephant by creating incentives that increase short-term rewards, and shaping the path with social modeling and a resetting of social norms (Amel et al., 2017).

\section{Limitations}

There were several limitations to the intervention study. Whereas participants reported daily on completing each task and also reported a completion percentage at the end of the study, demand characteristics may have prevented participants from being honest about the rate of completion. All participants reported completing at least $60 \%$ of tasks; the conservation condition had $88 \%$ of participants completing over $80 \%$ of the tasks, while $82 \%$ of the ecological attachment condition reported completing over $80 \%$ of the tasks. This means that compliance to the daily intervention was not perfect. Second, although it has been shown that interventions spanning at least 3 weeks have been associated with significant changes in responses of participants (e.g., Miu \&t Yeager, 2015), participants may have found the length of the intervention overly taxing, thus decreasing compliance.

The study involved behaviors that college students could carry out in their environment even after the study ended. But we did not control the time of year participation occurred. Perhaps our intervention would be most effective for students who are beginning the school year and moving into a new residence and beginning new routines. The habit discontinuity hypothesis suggests that behavior change is most effective when it coincides with other life changes that cause temporary habit disruption, because at these times participants are more susceptible to adopting a new mindset conducive to behavior change (Bamberg, 2006; Verplanken, Walker, Davis, \&t
Jurasek, 2008; Walker, Thomas, \&t Verplanken, 2014). For example, those who had recently relocated households were more likely to adopt new sustainable behaviors (Verplanken \& Roy, 2013).

\section{Conclusion}

An Indigenous worldview is characteristic of sustainable societies around the world, some in existence for millennia or even tens of millennia (Lawlor, 1991; Suzman, 2017). It may be that in order to reverse the ecological catastrophes underway, humanity must return to the Indigenous worldview (Narvaez et al., 2019). The current studies suggest that acting with intentional awareness of ecological entities over the course of several weeks may aid in a return to the Indigenous worldview.

of course, increasing ecological attachment and mindfulness are not sufficient to change the larger system that contributes to environmental destruction. As Amel and colleagues (2017) point out, internal factors such as emotion, beliefs, and attitudes interact with contextual issues such as politics and social policy. Many environmentally destructive activities occur at the institutional and corporate levels (e.g., 90 businesses generate 63\% of global greenhouse emissions; Heede, 2014). While many interventions aim to shift values and emotion, powerful components of individual behavior, larger situational and contextual factors like the "social milieu" and surrounding infrastructure can remain unchanged by these internally focused behavior-change campaigns. Due to the intensity of the environmental crisis, broader implementation strategies are needed, such as community-based social marketing and storytelling that emphasize connection rather than separation and control. Exactly how individual components such as those examined here can impact the political and legal levels of a society needs investigation.

\section{Acknowledgments}

This work was supported by the Institute for Scholarship in the Liberal Arts, University of Notre Dame.

\section{Author Disclosure Statement}

No competing financial interests exist.

\section{Funding Information}

No funding was received for this article.

\section{REFERENCES}

Abrahamse, W., Steg, L., Vlek, C., \& Rothengatter, T. (2005). A review of intervention studies aimed at household energy conservation. Journal of Environmental Psychology, 25, 273-291. 
NATURE CONNECTION

Amel, E. L., Manning, C. M., \& Scott, B. A. (2009). Mindfulness and sustainable behavior: Pondering attention and awareness as means for increasing green behavior. Ecopsychology, 1, 14-25.

Amel, E., Manning, C., Scott, B., \&t Koger, S. (2017). Beyond the roots of human inaction: Fostering collective effort toward ecosystem conservation. Science, $356,275-279$.

Bamberg, S. (2006). Is a residential relocation a good opportunity to change people's travel behaviour? Results from a theory-driven intervention study. Environment and Behaviour, 38, 820-840.

Berenguer, J. (2007). The effect of empathy on pro-environmental attitudes and behaviors. Environment and Behavior, 39, 269-283.

Berkes, F., Folke, C., \& Gadgil, M. (1995). Traditional ecological knowledge, biodiversity, resilience and sustainability. In C. A. Perrings, K. G. Mäler, C. Folke, C. S. Holling, \& B. O. Jansson (Eds.), Biodiversity conservation. Ecology, economy \&t environment (Vol. 4, pp. 269-287). Dordrecht, the Netherlands: Springer.

Bernstein, J. M., Szuster, B., \& Phillips, L. (2017). Assessing the diversity of contemporary environmentalism: Time for a new paradigm. International Journal of Environmental Research, 11, 641-652.

Berry, W. (2013). It all turns on affection. 2012 Jefferson Lecture. Washington, DC: National Endowment for the Humanities.

Black, J. S., Stern, P. C., \&t Elworth, J. T. (1985). Personal and contextual influences on household energy adaptations. Journal of Applied Psychology, 70, 3-21.

Booth, A. (2000). Ways of knowing: Acceptable understandings within bioregionalism, deep ecology, ecofeminism, and Native American cultures. Trumpeter, 16(1).

Bragg, E. A. (1996). Towards ecological self: Deep ecology meets constructionist self-theory. Journal of Environmental Psychology, 16, 93-108.

Bratt, C. (1999). The impact of norms and assumed consequences on recycling behavior. Environment and Behavior, 31, 630-656.

Brown, K. W., \&t Kasser, T. (2005). Are psychological and ecological well-being compatible? The role of values, mindfulness, and lifestyle. Social Indicators Research, 74, 349-368.

Burns, H. L. (2015). Transformative sustainability pedagogy: Learning from ecological systems and indigenous wisdom. Journal of Transformative Education, 13, 259-276

Cahalan, W. (1995). Ecological groundedness in Gestalt therapy. In T. Roszack, M. E. Gomes, \& A. D. Kanner (Eds.), Ecopsychology: Restoring the earth, healing the mind (pp. 216-223). San Francisco, CA: Sierra Club.

Cajete, G. (2000). Native science: Natural laws of interdependence. Santa Fe, NM: Clear Light.

Coburn, M. (2006). Walking home: Women's transformative experiences in the wilderness of the Appalachian Trail. Dissertation Abstracts International: Section B. The Sciences and Engineering, 67, 2857.

Cooper, T. (1998). A time before deception: Truth in communication, culture, and ethics. Santa Fe, NM: Clear Light Publications.

Cooper Marcus, C., \&t Barnes, M. (1999). Introduction: Historical and cultural perspective on healing gardens. In C. Cooper Marcus \& M. Barnes (Eds.), Healing gardens: Therapeutic benefits and design recommendations (pp. 1-26). New York, NY: John Wiley \& Sons.

Costanzo, M., Archer, D., Aronson, E., \&t Pettigrew, T. (1986). Energy conservation behavior: The difficult path from information to action. American Psychologist, $41,521-528$.
Davis, M. H. (1983). Measuring individual differences in empathy: Evidence for a multidimensional approach. Journal of Personality and Social Psychology, 44, $113-126$

Deloria, V. (2006). The world we used to live in. Golden, CO: Fulcrum Publishing.

Descola, P. (2013). Beyond nature and culture (J. Lloyd, trans.). Chicago, IL: University of Chicago Press.

De Wet, M. J. (2008). An exploration of modern consumer society and a guide towards mindful consuming. Dissertation Abstracts International, 69(3-B), 1948.

Dietz, T. M., Fitzgerald, A., \& Shwom, R. (2005). Environmental values. Annual Review of Environment \& Resources, 30, 1-38.

Dunlap, R. E., Van Liere, K. D., Mertig, A. G., \& Jones, R. E. (2000). Measuring endorsement of the new ecological paradigm: A revised NEP scale. Journal of Social Issues, 56, 425-442.

Four Arrows. (2016). Point of departure. Charlotte, NC: Information Age Publishing.

Four Arrows, \&t Narvaez, D. (2016). Reclaiming our indigenous worldview: A more authentic baseline for social/ecological justice work in education. In N. McCrary \& W. Ross (Eds.), Working for social justice inside and outside the classroom (pp. 93-112). Volume 2 in S. J. Miller \& L. D. Burns (Series Eds.), Social justice across contexts in education. New York, NY: Peter Lang.

Gifford, R. (2011). The dragons of inaction: Psychological barriers that limit climate change mitigation and adaptation. American Psychologist, 66, doi:10.1037/a0023566

Goh, E., Ritchie, B., \&t Wang, J. (2017). Non-compliance in national parks: An extension of the theory of planned behavior model with pro-environmental values. Tourism Management, 59, 123-127.

Goleman, D. (2009). Ecological intelligence: How knowing the hidden impacts of what we buy can change everything. New York, NY: Doubleday.

Hansla, A., Gamble, A., Juliusson, A., \& Garling, T. (2008). The relationships between awareness of consequences, environmental concern, and value orientations. Journal of Environmental Psychology, 28, 1-9.

Hanss, D., \& Bohm, G. (2013). Promoting purchases of sustainable groceries: An intervention study. Journal of Environmental Psychology, 33, 53-67.

Heath, C., \& Heath, D. (2010). Switch: How to change things when change is hard. New York, NY: Crown.

Heede, R. (2014). Tracing anthropogenic carbon dioxide and methane emissions to fossil fuel and cement producers, 1854-2010. Climatic Change, 122, 229-241.

Kaiser, F. G., Ranney, M., Hartig, T., \&t Bowler, P. (1999). Ecological behavior, environmental attitude, and feelings of responsibility for the environment. European Psychologist, 4, 59-74.

Kidner, D. W. (2001). Nature and psyche: Radical environmentalism and the politics of subjectivity. Albany, NY: State University of New York Press.

Koger, S. M., \&t Winter, D. D. N. (2010). The psychology of environmental problems (3rd ed.). New York, NY: Psychology Press, Taylor and Francis Group.

Kollmuss, A., \& Agyeman, J. (2002). Mind the gap: Why do people act environmentally and what are the barriers to pro-environmental behavior? Environmental Education Research, 8, 239-260.

LaLonde, R., \& Jackson, E.L. (2002) The new environmental paradigm scale: has it outlived its usefulness? The Journal of Environmental Education, 33, 28-36.

Lauren, N., Fielding, K. S., Smith, L., Louis, W. R. (2016) You did, so you can and you will: Self-efficacy as a mediator of spillover from easy to more difficult proenvironmental behaviour. Journal of Environmental Psychology, 48, 191-199.

Lawlor, R. (1991). Voices of the first day: Awakening in the Aboriginal Dreamtime. Rochester, VT: Inner Traditions. 


\section{KURTH ET AL.}

Macy, J., \& Brown, M. Y. (1998). Coming back to life: Practices to reconnect our lives to our world. Gabriola Island, BC: New Society Publishers.

Mayer, F. S., \& Frantz, C. M. (2004). The Connectedness to Nature Scale: A measure of individuals' feeling in community with nature. Journal of Environmental Psychology, 24, 503-515.

Mayer, F. S., Frantz, C. M., BruehIman-Senecal, E., \& Dolliver, K. (2009). Why is nature beneficial: The role of connectedness to nature. Environment and Behavior, 41, 607-643.

Merchant, C. (1983). The death of nature: Women, ecology and the scientific revolution. New York, NY: Harper \& Row.

Miu, A. S., \& Yeager, D. S. (2015). Preventing symptoms of depression by teaching adolescents that people can change: Effects of a brief incremental theory of personality intervention at 9-month follow-up. Clinical Psychological Science, 3, 726-743.

Moore, J. (2015). Capitalism in the web of life: Ecology and the accumulation of capital. London: Versa.

Nadasdy, P. (2005). Transcending the debate over the ecologically noble Indian: Indigenous peoples and environmentalism. Ethnohistory, 52, 291-331.

Naess, A. (1973). The shallow and the deep, long range ecology movements: A summary. Inquiry, 16, 95-100.

Naess, A. (1985). Identification as a source of deep ecological attitudes. In M. Tobias (Ed.), Deep ecology (pp. 256-270). San Diego, CA: Avant Books.

Narvaez, D., Four Arrows, Halton, E., Collier, B., \&t Enderle, G. (Eds.) (2019). Indigenous sustainable wisdom: First Nation know-how for global flourishing. New York, NY: Peter Lang.

Pearce, T., Ford, J., Willox, A.C., \& Smit, B. (2015). Inuit traditional ecological knowledge (TEK) subsistence hunting and adaptation to climate change in the Canadian arctic. Arctic, 68, 141-282.

R Core Team. (2016). R: A language and environment for statistical computing. Vienna, Austria: R Foundation for Statistical Computing. Retrieved from http:// www.R-project.org

Redfield, R. (1953). The primitive world and its transformations. Ithaca, NY: Cornell University Press.

Ro, M., Brauer, M., Kuntz, K., Shukla, R., \&t Bensch, I. (2017). Making cool choices for sustainability: Testing the effectiveness of a game-based approach to promoting pro-environmental behaviors. Journal of Environmental Psychology, 53, 20-30.

Rosseel, Y. (2012). lavaan: An R package for structural equation modeling. Journal of Statistical Software, 48, 1-36.

Schultz, P. W. (2000). Empathizing with nature: The effect of perspective taking on concern for environmental issues. Journal of Social Issues, 56, 391-406.

Seed, J., Macy, J., Fleming, P., \& Naess, A. (1988). Thinking like a mountain: Towards a council of all beings. Philadelphia, PA: New Society Publishers.

Sevillano, V., Aragones, J. I., \& Schultz, P. W. (2006). Perspective taking, environmental concern, and the moderating role of dispositional empathy. Environment and Behavior, 39, 385-705.

Stern, P. C. (2000). Psychology and the science of human-environment interactions. American Psychologist, 47, 1224-1232.

Stern, P. C., Dietz, T., \& Kalof, L. (1993). Value orientations, gender, and environmental concern. Environment and Behavior, 25, 322-348.

Suzman, J. (2017). Affluence without abundance: The disappearing world of the Bushmen. New York, NY: Bloomsbury.

Swanson, J. (2001). Communing with nature. Corvallis, OR: Illahee Press.
Tabanero, C., \&t Hernandez, B. (2011). Self-efficacy and intrinsic motivation guiding environmental behavior. Environment and Behavior, 43, 658-675.

Verplanken, B., \&t Roy, D. (2013). "My worries are rational, climate change is not": Habitual ecological worrying is an adaptive response. PLOS ONE, doi:10.1371/ journal.pone.0074708

Verplanken, B., Walker, I., Davis, A., \& Jurasek, M. (2008). Context change and travel mode choice: Combining the habit discontinuity and self-activation hypotheses. Journal of Environmental Psychology, 28, 121-127.

Walker, I., Thomas, G. O., \& Verplanken, B. (2014). Old habits die hard: Travel habit formation and decay during an office relocation. Environment \& Behaviour, 47, 1089-1106.

Widegren, 0. (1998). The new environmental paradigm and personal norms. Environment and Behavior, 30, 75-100.

Williams, K. J., Et Harvey, D. (2001). Transcendent experience in forest environments. Journal of Environmental Psychology, 21, 249-260.

WindEagle \& RainbowHawk. (2003). Heart seeds: A message from the ancestors. Edina, MN: Beaver's Pond Press.

Worster, D. (1994). Nature's economy: A history of ecological ideas (2nd ed.). Cambridge, UK: Cambridge University Press.

Wulf, A. (2015). The invention of nature: Alexander von Humboldt's new world. New York, NY: Knopf.

Yuan, K. H., \&t Bentler, P. M. (2000). Three likelihood-based methods for mean and covariance structure analysis with nonnormal missing data. Sociological Methodology, 30, 165-200.

Address correspondence to: Darcia Narvaez

Department of Psychology University of Notre Dame 390 Corbett Family Hall Notre Dame, IN 46556

USA

E-mail:dnarvaez@nd.edu

Received: August 1, 2019

Accepted: October 5, 2019

\section{Appendix A1.}

\section{Ecological Empathy}

We are interested in your experience. Please respond according to the frequency of your feelings in the past week.
1 Never
2 On one day
3 On several days
4 Every day 
NATURE CONNECTION

\section{Multiple times a day}

In the past week, I felt concern for ...

1. ...the natural world

2. .... a particular species

3. ... an animal going extinct

4. ... an animal I don't know

5. ....an insect

6. .... a tree

7. .... a forest

8. ... a plant

9. ....a mountain

10. .... a river

11. ... a lake or pond

12. ...the ocean(s)

13. ...biodiversity

14. ...groups of animals

15. ...groups of plants

16. ...the wellbeing of the earth

\section{Ecological Mindfulness}

We are interested in your experience. Please respond according to the frequency of your experience in the past week.

1 Never

2 On one day

3 On several days

4 Every day

5 Multiple times a day

In the past week, I ...

1. Treated animals like my brothers and sisters

2. Showed respect for a plant

3. Recognized a wild animal around my home

4. Paid attention to the habitat of animals and plants around my home

5. Respected Nature

6. Tried to live as a partner with Nature

7. Felt responsible for the wellbeing of Nature

8. Respected the living things around me

9. Cared for the landscape of nonhuman entities where I live

10. Tried to be mindful of earth care wherever I was

11. Made decisions guided by their effects on the natural world

12. Made decisions with humility as one of many earth creatures

13. Acted with awareness of the needs of biodiversity
14. Acted with awareness of the needs of animals

15. Acted with awareness of the needs of plants

\section{Daily Green Action Index}

Please indicate how often you have taken the action listed.

1 Never

2 Once or twice

3 Three or four times

4 Every day

5 Multiple times a day

In the past week, I ...

1. Turned the tap off when brushing teeth and shaving

2. Turned off the lights or television when I left the room

3. Unplugged phone and computer chargers after use

4. Unplugged phone as soon as it is charged

5. Biked, walked, or used mass transit instead of driving

6. Composted organic waste

7. Washed in cold or warm water instead of hot

8. Used cloth instead of paper napkins

9. Took shorter showers

10. Printed double sided

11. Used reusable water bottle / coffee mug

12. Encouraged others to make eco-friendly choices

13. Used scratch paper instead of fresh paper whenever possible

14. Washed dishes by hand instead of using a dishwasher

15. Let my hair dry naturally instead of using the hair dryer

16. Used natural cleaners (e.g., lemon juice, vinegar) instead of chemical cleaners

17. Avoided using plastic

18. Practiced slow food (home cooking) instead of fast food

19. Carpooled

20. Avoided excess packaging in what I purchased

21. Consumed only animal-friendly products

22. Made an effort to not eat meat

23. Tried to avoid buying anything I didn't really need

24. Put recyclable materials into recycling instead of the trash

25. Used reusable bags for shopping

26. Bought locally grown products

27. Hung up washed clothes to dry instead of using the dryer

28. Made my own personal products instead of buying them premade (e.g., shampoo)

29. Purposefully purchased fair trade products

30. Used biodegradable soap, shampoos 


\section{KURTH ET AL.}

31. Reduced use of disposable products by using reusable containers

32. If I needed to buy disposable products, I chose paper or glass products instead of plastic

33. Considered the footprint of products before I bought them: from resource extraction to production, distribution, consumption, and disposal

34. Actively tried to simplify my life

35. Drank tap water instead of bottled water

36. Avoided using heating/cooling system and changed clothing instead

\section{Green Action Index}

Please indicate how often you have taken the action listed.

\author{
1 Never \\ 2 Once \\ 3 Two times \\ 4 3-4 times \\ 5 5-8 times \\ 6 6-12 times \\ 7 More than 12 times
}

In the past six months, I ...

1. Sought information on how to live a more eco-friendly life

2. Donated old clothes

3. Purchased used and secondhand items

4. Recycled batteries

5. Grew my own vegetables

6. Contacted a business to complain about the effects of their products on the environment

7. Tried to decrease my desires for products that are harmful to the environment

8. Tried to decrease my effects on the local ecology (e.g., did not kill insects but put them outside)

9. Took actions to encourage biodiversity (e.g., organic lawn care)

10. Avoided using products that are toxic to living organisms (e.g., pesticides, insecticides, soaps with phosphates, mineral oil)

11. Advocated ecologically responsible actions to higher-ups (e.g., boss, political leaders)

12. Replaced incandescent light bulbs with energy-efficient bulbs

13. Participated in an environmental awareness day in my community
14. Wrote to my lawmakers or elected officials urging them to act with urgency and put care for the environment

15. Encouraged my community to support mass transit and other alternatives to the automobile for commuting

\section{Appendix A2.}

\section{Action Items by Intervention Condition}

We are comparing different types of interventions. We would like you to select 21 slips of paper for a "suggestion pile" from which you will be selecting for the next 3 weeks. Select one each day of 21 days. Please choose actions that you could improve upon.

Each day we will send an email reminder to select a slip from the envelope. Write the date on which you practiced the action.

\section{Condition 1: Conservation}

1. Turn the water tap off when brushing teeth.

2. Turn water tap off when shaving.

3. Turn off the lights when you leave the room.

4. Turn off TV when you leave the room.

5. Unplug phone charger after phone is charged.

6. Unplug computer charger after computer is charged.

7. Wash clothes in cold or warm water instead of hot.

8. Take short showers.

9. Print paper double sided.

10. Use reusable water bottle / coffee mug [check _ here if you do NOT have one].

11. Use scratch paper instead of fresh paper whenever possible.

12. Use electronic submission instead of paper submission for your assignments.

13. Put recyclable materials into recycling instead of the trash

14. Reduce use of disposable products by using reusable containers

15. Drink tap water instead of bottled water

16. Turn off electronics for a set period of time today.

17. Change clothes instead of changing the thermostat.

18. Take only the food you will eat at the dining hall (don't throw any food away).

19. Don't waste water.

20. Only buy things you really need.

21. Read books electronically instead of hardcopy.

22. Reuse things in creative ways.

23. Recycle whatever is recyclable.

24. Avoid using a hair dryer. 
NATURE CONNECTION

25. Avoid using an iron.

26. Only use the resources you need (don't waste, light, water, energy).

\section{Condition 2: Ecological attachment items}

1. Establish a relationship with a tree near your dorm. Say hello every time you pass it. Observe its wellbeing.

2. Think about your tree friend's life-how she looked 10 years ago and how she will look in 20 years.

3. Notice the color of the sky throughout the day.

4. Notice the clouds throughout the day.

5. When you eat your meals, thank all the life-forms that contribute your meal.

6. Give thanks for the living things that make up your clothes.

7. Give thanks for the living things that make up your furniture.

8. Sit outside for five minutes and listen to nature sounds [sit spot].

9. Sit outside for five minutes and watch nature [sit spot].

10. Sit outside for five minutes and smell the smells [sit spot].

11. Think of a favorite plant in your life and feel gratitude for its life and for its gift to you.

12. Think of a favorite animal in your life and feel gratitude for its life and for its gift to you.

13. Take a walk around the lake today.

14. Pay attention to the sunlight today, how it reflects and dances on trees, etc.

15. Pay attention to the winds today, how they shift and move trees, etc.

16. Face each of the four directions each morning, take a breath and give thanks for the life-forms in that direction.

17. The four elements are water, air, fire, and earth.

18. Give thanks for the element of water today. What bodies of water are you grateful for?

19. Give thanks for the element of fire today, for the sun and its warmth.
20. Give thanks for the element of earth today, for the earth's sustenance of all.

21. Give thanks for the element of air today, for the winds that carry life and cleansing.

22. Notice the day: the wind, the sun and the light, the ground and the snow, the moisture and the water.

23. Breathe in deeply.

24. Figure out what phase the moon is in.

25. Walk outside for 5-10 minutes; notice and appreciate the sights of nature.

26. Walk outside for 5-10 minutes; notice and appreciate the sounds of nature.

27. Walk outside for 5-10 minutes; notice and appreciate the smells of nature.

28. Look closely at one part of nature today (e.g., pine cone, square of earth, plant, rock).

29. Say hello to the animals you see today.

30. Consider how many different forms of life you can see from your window.

31. Compare and contrast the types of plants and animals you see on campus and at home.

32. Acknowledge trees today, bare branches against the blue sky.

33. Acknowledge the bushes you see today.

34. Consider the ground today, wherever you step. Notice its condition (frozen, muddy, etc.).

35. Stop and watch a bird today.

36. Notice the relationships among living things: squirrel to tree, tree to earth, tree to sky.

37. Touch a tree. Approach another tree and ask permission to touch the tree. Pay attention to and honor the answer.

38. Find a pleasant spot to sit outside, close eyes, breathe deeply; notice how the elements feel on your skin (turn off electronics).

39. Minimize harm to living things.

40. Find a beautiful spot in nature and take a photo or make a drawing. 